University of Nebraska - Lincoln

DigitalCommons@University of Nebraska - Lincoln

Faculty Papers and Publications in Animal

Science

Animal Science Department

1993

\title{
Alternative Methods of Selection for Litter Size in Mice: III. Response to 21 Generations of Selection
}

Yvonne Kochera Kirby

Northwestern University

Merlyn K. Nielsen

University of Nebraska-Lincoln, mnielsen1@unl.edu

Follow this and additional works at: https://digitalcommons.unl.edu/animalscifacpub

Part of the Animal Sciences Commons

Kochera Kirby, Yvonne and Nielsen, Merlyn K., "Alternative Methods of Selection for Litter Size in Mice: III. Response to 21 Generations of Selection" (1993). Faculty Papers and Publications in Animal Science. 483.

https://digitalcommons.unl.edu/animalscifacpub/483

This Article is brought to you for free and open access by the Animal Science Department at DigitalCommons@University of Nebraska - Lincoln. It has been accepted for inclusion in Faculty Papers and Publications in Animal Science by an authorized administrator of DigitalCommons@University of Nebraska - Lincoln. 


\title{
Alternative Methods of Selection for Litter Size in Mice: III. Response to 21 Generations of Selection ${ }^{1,2}$
}

\author{
Yvonne Kochera Kirby ${ }^{3}$ and M. K. Nielsen4 \\ Department of Animal Science, University of Nebraska, Lincoln 68583-0908
}

\begin{abstract}
Alternative methods of selection to increase litter size in mice have been practiced for 21 generations followed by six generations of relaxed selection. Three replicates were used with four selection criteria: index of components (IX: $I=1.21 \times$ total ovulation rate $+9.05 \times$ ova success), uterine capacity (UT), litter size (LS), and an unselected control (LC). In IX, ovulation rate and ova success were measured by number of corpora lutea and number of pups born/number of corpora lutea, respectively. In UT, uterine capacity was measured and defined as number of pups born to unilaterally ovariectomized (right ovary excised) females. Selection in LS was based on number born to unaltered dams. In all cases, number born was fully formed, live or dead pups. Pups from 16 randomly chosen LC dams and from the top 16 dams in IX, UT, and LS were selected to produce the next generation in each criterion-replicate line.
\end{abstract}

Response in number born, selected criteria deviated from control, was regressed on generation number over the 21 generations of selection. Responses for the IX and LS criteria were quite similar $(.14 \pm .01$ and $.16 \pm .01$ pups per generation, respectively), whereas response in UT, with only one functional horn, was slightly lower $(.09 \pm .01)$. The average cumulative selection differentials for IX, LS, and UT at Generation 21 were 32.78 index units, 36.38 pups, and 28.53 pups, respectively. The LC criterion had an unintentional cumulative selection differential of 3.3 pups. Regressions of response in number born (litter size in IX and LS, uterine capacity in UT) on cumulative selection differential for IX, LS, and UT were $.10 \pm .01$, $.10 \pm .01$, and $.08 \pm .01$, respectively. During the relaxed selection, mean responses for litter size in IX, LS, and UT criteria were $3.17,4.09$, and 1.67 pups, respectively.

Key Words: Mice, Selection, Litter Size, Ovulation, Embryonic Mortality, Uterus

J. Anim. Sci. 1993. 71:571-578

\section{Introduction}

The productivity of a dam can be measured by the number of progeny weaned per gestation and can be enhanced by increasing the number of offspring born. Efforts to increase litter size include crossbreeding schemes and selection to increase live births, ovulation rate, or embryonic survival. The results have been variable. Using divergent selection for litter size in mice, Falconer $(1960,1971)$ concluded that responses were due to changes in ovulation rate and prenatal

\footnotetext{
${ }^{1}$ Published as paper no. 9915, Journal Ser., Nebraska Agric. Res. Div., Univ. of Nebraska, Lincoln 68583-0908.

2 Appreciation is expressed to Jeryl Hauptman for maintaining the animal population and aiding in data collection.

${ }^{3}$ Present address: Dept. of Neurobiol. and Physiol., Northwestern Univ., 2153 Sheridan Road, Evanston, IL 60208-3500.

${ }^{4}$ To whom correspondence should be addressed: A218 Animal Sciences.

Received April 2, 1992.

Accepted October 5, 1992.
}

mortality. Prenatal mortality can in part be due to the number of embryos exceeding the capacity of the uterus (Bennett and Leymaster, 1989); thus, if uterine capacity increased so would litter size.

Johnson et al. (1984) described litter size as a natural, but not necessarily optimal, index of ovulation rate and embryonic survival. By optimizing the relative emphasis on the components using index selection, number born should increase at a faster rate than it would if one selected directly for litter size. Selection on number born in unilaterally ovariectomized female mice (Clutter et al., 1990) has been proposed as a means to change uterine capacity, following the suggestions of Christenson et al. (1987) and Bennett and Leymaster (1989).

A previous paper (Gion et al., 1990) presented responses to selection through 13 generations in mice using three alternative criteria: an index of components, uterine capacity, and litter size. The purpose of this paper is to present responses and estimates of response per selection applied after 21 generations in the same selection lines. 


\section{Experimental Procedures}

Generation of Lines and General Procedures. The population used in this study was outbred CF1 mice (SASCO, Omaha, NE). Estimations of base population parameters were reported by Clutter et al. (1990). The population was partitioned into three replicates and then into four lines within each replicate; line in this paper will refer to a replicatecriterion population.

The replicates were separated in time by 4 wk. A 12-wk generation interval was used with performance measured only at first parity. The laboratory was kept at $24^{\circ} \mathrm{C}$ with $12 \mathrm{~h}$ light:12 $\mathrm{h}$ dark cycles. Animals in littering cages had ad libitum access to a rodent-block diet containing $20 \% \mathrm{CP}, 10 \%$ fat, and $2 \%$ crude fiber. Animals in growing and breeding cages had ad libitum access to a rodent-block diet containing $24 \% \mathrm{CP}, 4 \%$ fat, and $4.5 \%$ crude fiber.

Selection Methods. The selection criteria, population sizes, and general procedures were described in detail by Gion et al. (1990). One criterion was a randomly selected control ( LC) in which each of the 16 families in a line contributed a daughter and a son to the parents for the next generation. Through the first nine generations, 30 to 32 females were measured per generation per line; after that 60 to 70 females were measured. For the three criteria having intentional selection (index of components $[\mathbf{I X}]$, uterine capacity [UT], and litter size [LS]), between 70 and 100 females were measured each generation with the top 16 , or occasionally 17 , litters selected to produce the next generation. Matings were assigned to minimize inbreeding. Body weight at mating (approximately 9 wk) was recorded on all females. Litter size was standardized to 10 within $1 \mathrm{~d}$ of birth, in an attempt to approach an ideal number of seven females per litter in the selection criteria and five females in LC.

The IX criterion was an index of ovulation rate and ova success (proportion of ova represented by pups born), as suggested by Johnson et al. (1984). The index ( $\mathrm{I}=1.21 \times$ ovulation rate $+9.05 \times$ ova success $)$ was derived from estimates of population parameters in the base population. Clutter et al. (1990) showed that this was the optimum linear criterion for the nonlinear objective of ovulation rate and ova success. The index weightings were scaled such that the standard deviation of the index was expected to be the same as that for litter size. Ovulation rate was measured as number of corpora lutea on both ovaries excised at $18 \mathrm{~d}$ of gestation. Ova success was determined after birth of the pups the following day.

The UT criterion was number born to unilaterally ovariectomized females. The right ovary of each female was excised at 4 wk. Clutter et al. (1990) described the rationale for this physiological model as an attempt to measure uterine capacity (all embryos are restricted to the left uterine horn). The LS criterion was number born in unaltered females, hence traditional selection for litter size. Number born in all cases included live and dead, fully formed pups.

Relaxed Selection. Data from Generations 22 through 27 are also included in this paper. Beginning in Generation 22, the number of litters per line that contributed breeders was increased from 16 to 32 per generation. One male and two females were randomly drawn as breeders from each litter; thus, up to 64 females were measured in each generation for each line. One sister's litter from the pair was randomly selected to contribute to the next generation. The generation interval was kept at 12 wk with the three replicates still separated in time by 4 wk. Females in the UT criterion did not have unilateral ovariectomies and ovulation rate was not measured in IX; thus, the number born for all criteria was recorded on unaltered females.

Statistical Analyses. Changes due to selection were evaluated by regressing the generation means for the given trait on generation number and also by deviating the generation means of the trait from the control and then regressing the difference on generation number. Traits evaluated using the deviation in selected criteria from the control were total number born, female $\mathrm{BW}$ at mating, number of females born alive, number of males born alive, and number of pups born dead. Total number born was the same as litter size (unaltered females) for all generations in LS, LC, and IX and for Generations 22 through 27 in UT. During Generations 0 through 21 in UT, number born was measured on altered (unilaterally ovariectomized) females and called uterine capacity. Data that were collected each generation ( 0 through 20 ) in the IX criterion (left corpora lutea, right corpora lutea, total corpora lutea, total ova success, and the index value) but not collected for the other three criteria were evaluated by regressing the generation means on generation number. To evaluate the relationship between litter size and BW for each criterion, the generation mean of each line for total number of pups born was regressed on female BW at mating.

Total number born, expressed as a deviation from control, was regressed on the cumulative selection differential, deviated from the control, over 21 generations of selection. The unit of measure for the selection differential in the LS, UT, and LC criteria was number of pups born (litter size in LS and LC, but uterine capacity in UT), and in the IX criterion unit of measure was index value. Cumulative selection differentials were calculated by the method described by Gion et al. (1990), which considers both "female" and "male" selection differentials for a sex-limited trait, weighted by numbers of progeny ad grandprogeny measured. Cumulative selection differentials were also calculated for female mating weight.

Two other approximations of response per selection applied were calculated using the cumulative selection after 21 generations. One was the ratio of response in 
Generation 21 to the cumulative selection differential. Because number born in the UT criterion was in altered females (uterine capacity), Generation 21 response was corrected for the initial (Generation 0 ) difference between UT and LC. The other was the ratio of the average response (litter size in all criteria) measured over Generations 22 through 27 to the cumulative selection differential at Generation 21. All responses and cumulative selection differentials were deviated from LC for IX, LS, and UT.

All regressions on generation number and cumulative selection differential and ratios to the total cumulative selection differential were calculated by replicate. The three replicates' values were averaged, with standard errors derived empirically from the variability between replicates, thus accounting for variability due to drift. The average estimates were then tested for significance from zero using a $t$ distribution with $2 \mathrm{df}$.

Data for number born during Generations 22 through 27 were analyzed with a model fitting generation, replicate, criterion, and replicate $x$ criterion. The replicate $x$ criterion interaction was used as the test term for differences between criteria, again to account for drift variability. The criterion sums of squares were separated into three orthogonal contrasts: the effect of selection (IX, LS, and UT vs LC), selection for litter size compared to uterine capacity only (IX and LS vs UT), and method of selection for total litter size (IX vs LS).

Fertility or pregnancy rate data were analyzed in three analyses. The first was with a model fitting replicate, criterion, the linear and quadratic effects of generation, and all interactions. The data in this analysis were the 21 generations of selection, and tests for criteria and the criterion $\times$ regression interactions were done using the replicate $x$ criterion and replicate $\times$ criterion $\times$ regression interactions, respectively. The other two analyses used the same model ignoring generations: replicate, criterion, and replicate $\times$ criterion (test term for criteria differences). This model was applied to two data sets: the last seven generations of selection (15 through 21) and the seven generations of relaxed selection ( 22 through 27).

\section{Results and Discussion}

Selection Applied. Realized cumulative selection differentials for total number born and index values across all criteria are given in Table 1 . Selection applied was very steady in all criteria throughout the experiment, as can be seen in the cumulative selection through 5, 9, 13, 17, and 21 generations. Realized selection differentials ranged from 97 to $99 \%$ of the intended differentials. Intended differentials were those calculated from the average superiority of the top 16 females each generation in the IX, LS, and UT
Table 1. Realized cumulative selection differentials for number born ${ }^{a}$ and index value ${ }^{b}$ at various generations for each selection criterion, averaged across replicates

\begin{tabular}{lrrrrr}
\hline \hline \multirow{2}{*}{$\begin{array}{l}\text { Selection } \\
\text { criterion }^{\mathrm{c}}\end{array}$} & \multicolumn{5}{c}{ Generation } \\
\cline { 2 - 6 } & \multicolumn{1}{c}{5} & \multicolumn{1}{c}{9} & \multicolumn{1}{c}{13} & \multicolumn{1}{c}{17} & \multicolumn{1}{c}{21} \\
\hline LS $^{\mathrm{a}}$ & 8.12 & 14.83 & 21.68 & 29.18 & 36.38 \\
UT $^{\mathrm{a}}$ & 6.98 & 12.32 & 17.51 & 22.97 & 28.53 \\
LC $^{\mathrm{a}}$ & .26 & .07 & 1.27 & 2.51 & 3.28 \\
IX $^{\text {ad }}$ & 6.11 & 11.28 & 16.13 & 22.01 & 27.34 \\
IX $^{\mathrm{b}}$ & 7.35 & 13.21 & 19.30 & 25.92 & 32.77 \\
\hline
\end{tabular}

${ }^{\mathrm{a}}$ Units $=$ pups.

bunits = index values.

${ }^{\text {cLS }}$ = litter size; UT = uterine capacity; IX = index; LC = control.

${ }^{\mathrm{d}}$ Correlated selection differential for number born.

criteria. Realized selection was also quite uniform across replicates with a $\mathrm{CV}$ of 4 to $5 \%$ in the three selection criteria.

The realized selection differential for LC denotes the amount of unintended selection that occurred over the 21 generations in this criterion. Ideally this value would be zero. One reason that the LC criterion has experienced some selection pressure is because some of the randomly selected litters either did not have enough females or males to procreate the next generation or the litter did not survive to weaning. In either case, an alternate litter was chosen. These alternate litters tended to be larger and healthier.

The IX criterion had a realized selection differential for number born that was considerably lower than that of LS (Table 1). However, number born, in the IX criterion, was a correlated trait; selection was for index units, not for number of pups born. Criterion LS, compared with UT and IX, had the largest cumulative selection differential (consistent across replicates) because more pups were born alive and there was a higher survival rate from birth to mating (the IX pups were from induced parturitions and the UT pups from a more competitive uterine environment), and thus more females in the selected litters were available to measure in the next generation. Over the generations of selection, there was also increasing variability in the number born in LS. For example, in Generations 11 through 15 of all three replicates, the standard deviation of number born in the LS criterion was $20 \%$ greater than in LC, and variability in UT dropped $15 \%$ relative to LC.

In the early generations ( 0 through 3 ), the pooled within-replicate criterion (LS, LC, and IX) SD and $\mathrm{CV}$ for number born were 2.7 pups and $24 \%$, respectively. In the UT criterion in these same generations, the $\mathrm{SD}$ and $\mathrm{CV}$ for number born to unilaterally ovariectomized females (uterine capacity) were 2.8 pups and $29 \%$, respectively. The corresponding SD for index value in the IX criterion was 2.4 index units, which was lower than that for 


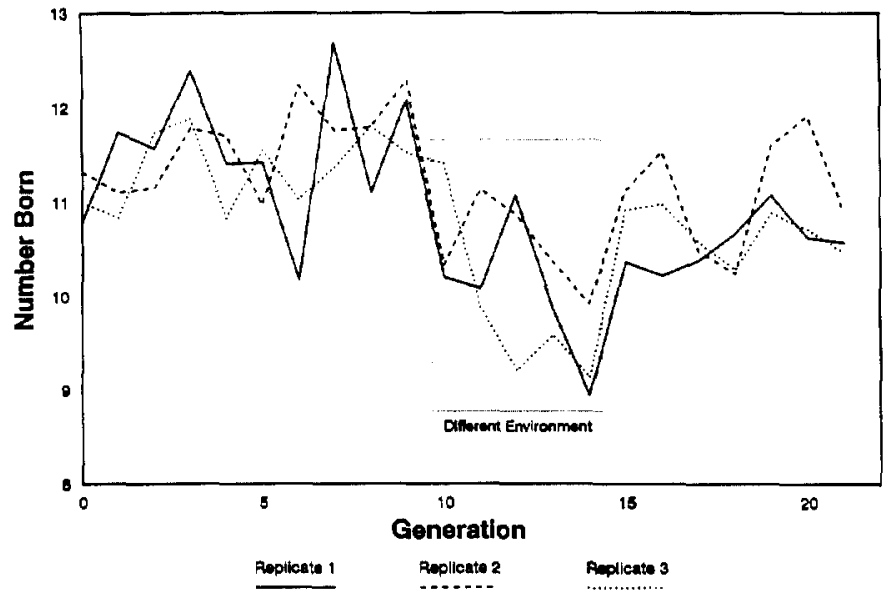

Figure 1. Number born in the unselected control (LC) by replicate across the 21 generations of selection. All lines were in temporary housing during Generations 10 through 14.

litter size even though that was the intention in scaling the index weightings.

Change in variability of the selection criteria over generations was also tested by regression for each criterion. The SD for number born in the LS criterion increased linearly $(P<.001)$ over generations, but there was no effect on the CV. In UT, both the SD and CV for number born changed quadratically $(P<.04)$ over generations with a positive quadratic coefficient. For LC, there was no change in the SD of number born over generations; however, due to the decreasing mean, the CV did increase linearly $(P<.04)$. For IX selection, the SD for both the index value $(P<.001)$ and number born $(P<.04)$ increased over generations of selection, but there was no change in $\mathrm{CV}$. In all criteria, there was no interaction of regressions with replicates.
The correlated realized selection differential for female mating weight in IX was approximately $18 \%$ higher than for LS, perhaps due to the emphasis of the index on ovulation rate. The realized differentials for UT were considerably smaller than those exhibited in the IX and LS criteria $(6.2,12.8$, and $10.8 \mathrm{~g}$, respectively) but larger than unintentional selection in LC $(.5 \mathrm{~g})$. The higher values in the IX and LS criteria are in agreement with the findings of Eisen and Durrant (1980); their study indicated that improved female reproductive performance, especially ovulation rate, was correlated with increased body size.

Control. Estimations of response are best made with data that have been deviated from the control criterion. Figure 1 illustrates a decrease in performance, approximately 1.3 pups, in the LC criterion from Generations 10 through 14. During this period, the mice were moved to temporary housing while the permanent laboratory was under renovation. After the mice were moved back to permanent housing, all lines exhibited approximately a one-pup increase, to about the same level of performance as before the move to temporary housing.

Response in Number Born. Table 2 and Figure 2 (selected criteria deviated from the control) detail how the selected lines have changed over the generations. Through 13 generations of selection, response in the IX criterion was similar to that in LS (.17 and .15 pups per generation, respectively), and UT (.10 pups per generation) was lower than IX and LS, but the trait measured was different. At Generation 0 the mean for number born in the UT criterion, with only one functional uterine horn, was about 2.2 pups less than the control. However, by Generation 13, UT was 1.3 pups less than the control, and by Generation 21 UT had increased total number born to within .26 pups of the control.

Table 2. Regression of response (selection criterion minus control) in number born on generation number and on cumulative selection differential, averaged across replicates

\begin{tabular}{lllll}
\hline \hline & \multicolumn{4}{c}{ Generations $^{b}$} \\
\cline { 2 - 4 } $\begin{array}{l}\text { Criterion } \\
\text { minus control }\end{array}$ & 0 to 13 & 13 to 21 & 0 to 21 & 22 to 27 \\
\hline & & Response on generation number & $.07 \pm .03$ \\
IX - LC & $.17 \pm .01^{* *}$ & $.13 \pm .04^{\dagger}$ & $.14 \pm .01^{* *}$ & $.07 \pm .08$ \\
LS - LC & $.15 \pm .04^{*}$ & $.25 \pm .03^{*}$ & $.16 \pm .02^{*}$ & $-.01 \pm .11$ \\
UT - LC & $.10 \pm .02^{*}$ & $.07 \pm .04$ & $.09 \pm .01^{* *}$ & - \\
& & Response on cumulative selection differential & - \\
IX - LC & $.12 \pm .01^{* *}$ & $.09 \pm .03^{\dagger}$ & $.10 \pm .01^{* *}$ & - \\
LS - LC & $.09 \pm .02^{*}$ & $.16 \pm .03^{*}$ & $.10 \pm .01^{*}$ & $.08 \pm .01^{* *}$ \\
UT - LC & $.08 \pm .02^{*}$ & $.07 \pm .03$ & .03
\end{tabular}

${ }^{a} \mathrm{IX}=$ index; LS = litter size; UT = uterine capacity; LC = control.

belection practiced through 21 generations, relaxed during Generations 22 to 27 .

${ }^{\dagger} P<.10$.

${ }^{*} P<.05$.

${ }^{* *} P<.01$. 
The difference between IX and LS responses at Generation 13 was reversed by Generation 21; LS and IX responses per generation over the full 21 generations were .16 and .14 additional pups, respectively. Between Generations 13 and 21 response per generation in LS was nearly double that of IX (.25 for LS and .13 for IX). This drop in response for IX was most likely due to using the same index throughout the 21 generations of selection, and changing population means and variances and covariances have probably altered the optimum index. Mean ovulation rate had changed from 13.2 in the base population used to derive the index to 16.4 averaged over the last three generations of selection in IX. Changes in the genetic and phenotypic variances and covariances have not been investigated yet; this is planned as a subsequent analysis. Rate of response in UT also dropped during Generations 13 to 21 of selection, apparently due to both lower variability and lower heritability. Rate in LS increased dramatically, due to a large increase in variability and heritability.

Regressions of the deviations of selected criteria from control on generation number during the six generations of relaxed selection were nonsignificant. In an analysis of line means over these six generations, contrasts of selection vs control (IX, LS, and UT vs LC), selection to improve litter size vs only uterine capacity (IX and LS vs UT), and the two methods of selection for total litter size (IX vs LS) were all significant at $P<.01, P<.01$, and $P<.10$, respectively. The overall means of selected criteria deviated from the control were as follows: IX $-\mathrm{LC}=$ 3.17; UT - LC $=1.67$; and LS $-\mathrm{LC}=4.09$ pups. Dividing these responses by 21 generations of selection yields $.15, .19$, and .08 pups per generation for IX, $\mathrm{LS}$, and UT, respectively.

Regressions of generation mean on generation number, for each criterion, were somewhat variable for total number born. However, when means for each selection criterion were deviated from the control means and then regressed on generation number,

Table 3. Ratio of response (selection criterion minus control) in number born in Generation 21 or the average of Generations 22 through 27 to the cumulative selection differential at Generation 21, averaged across replicates

\begin{tabular}{|c|c|c|}
\hline \multirow{2}{*}{$\begin{array}{l}\text { Criterion } \\
\text { minus control }{ }^{\mathrm{a}}\end{array}$} & \multicolumn{2}{|c|}{ Generation measured $^{b}$} \\
\hline & 21 & Mean 22-27 \\
\hline IX - LC & $.10 \pm .01^{*}$ & $.11 \pm .00^{* *}$ \\
\hline $\mathrm{LS}-\mathrm{LC}$ & $.10 \pm .01^{*}$ & $.12 \pm .01^{*}$ \\
\hline UT - LC & $.08 \pm .00^{* *}$ & $.07 \pm .01^{*}$ \\
\hline
\end{tabular}

${ }^{\mathrm{a}} \mathrm{IX}=$ index; $\mathrm{LS}=$ litter size; UT = uterine capacity; LC = control.

belection ceased at Generation 21.

${ }^{*} P<.05$.

$* * P<.01$

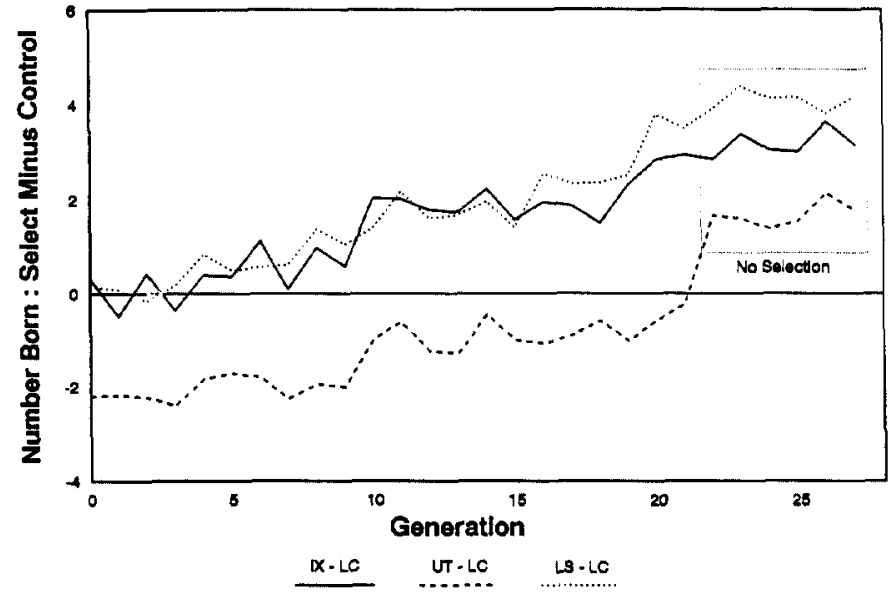

Figure 2. Number born (deviated from control) for the three selection criteria over the 21 generations of selection and six generations of relaxed selection. IX = index, UT = uterine capacity, and LS = litter size selection; LC $=$ unselected control.

much of the variation between replicates was reduced, particularly in the UT criterion. Regression of generation mean on generation number in LC yielded a slight, but significant $(P<.05)$, decrease in total number born, $-.05 \pm .01$, possibly due to the accumulation of inbreeding.

Response per Selection Applied. Table 2 also contains the regressions of response (selected criteria minus LC) on cumulative selection differential (corrected for LC). Through the first 13 generations, IX was higher than LS (.12 vs .09) and UT was the lowest (.08). During the interval of generations 13 to 21, LS selection was superior and UT continued to be the lowest, as expected, in response per selection applied. Over the full 21 generations, the regressions of response on cumulative selection were the same for IX and LS (.10) and lower for UT (.08). One must remember that response in IX and LS was for litter size and in UT response was for uterine capacity.

Table 3 indicates the estimates of response at the end of selection to the cumulative selection differential after 21 generations. Both response and selection applied in the selected criteria were deviated from LC values. The ratios using Generation 21 data were the same as the overall regressions for Generations 0 to 21 . Using the mean response during the six generations of relaxed selection produced similar estimates (.11 for IX, .12 for LS, and .07 for UT). During this interval (Generations 22 through 27), number born was on unaltered females in all criteria, whereas during the selection phase, it was on unilaterally ovariectomized (one functional uterine horn) females in UT. Response in UT for litter size per selection applied (.07) was only slightly lower than that for uterine capacity (.08); some reduction was expected given that uterine capacity is only a part of litter size. 
The difference in the corresponding regressions at 13 generations (Gion et al., 1990) was larger but in the same direction (.05 vs .08).

Even though the IX criterion dropped in effectiveness per selection applied during the final eight generations of selection, probably because of deviation from an optimal index as underlying parameters changed, and LS jumped to a much higher level, the overall (21 generations) response per selection differential was the same for IX and LS. If we had systematically altered the index with new estimates of the genetic and phenotypic variances and covariances and the component means, one would have expected to maintain the relative superiority of IX over LS found after 13 generations. A simulation study in swine by Bennett and Leymaster (1990) predicted a greater response using an index of components over direct selection for litter size when the index was routinely updated.

Live Female, Live Male, and Dead Pups. The number of females and males born alive tended to increase as selection continued. Regressions of the number of females and number of males born alive in IX, LS, and UT (deviated from LC) were $.07 \pm .01$ and $.03 \pm .01, .07 \pm .01$ and $.08 \pm .01$, and $.05 \pm .00$ and .05 \pm .00 pups per generation, respectively. All were significant $(P<.05)$ except the regression of IX males on generation number. In general, the number of males born alive in LS, UT, and LC tended to be greater than the number of females born alive.

Generation means for the number of pups born dead, as well as those means expressed as a deviation from the control, were regressed on generation number. The IX and LS criteria had positive but nonsignificant coefficients for both regressions. The UT and LC criteria both had decreases in number of pups born dead. However, only the UT criterion had significant $(P<.05)$ regressions on generation number for number born dead and its deviation from LC; the coefficients were small, $-.01 \pm .00$ pups born dead per generation. When total number born was held constant (adjusted by regression), the number born dead, across all criteria, was not significant. These results may indicate that selection for the UT criterion improved the uterine environment; thus, the ability of embryos (fetuses) to survive was enhanced. The observed changes in number of females and males born alive and number of pups born dead were not surprising because all four criteria changed significantly in total number born.

Components of Index Selection. The purpose of practicing selection using an index was to maximize the correlation of the index with breeding value for litter size; the resulting index gave weightings to ovulation rate and ova success different from those given by the natural index of litter size. This index produced the expected result of increasing ovulation rate (14 corpora lutea at Generation 0 to 17.4 at
Generation 20, the last generation measured) while maintaining ova success (average of .81 pups per corpus luteum) at the value of the base generation, thus yielding an increase in total number born. The regressions of means on generation number for index (.11 \pm .02 index units per generation), total corpora lutea (.09 \pm .01 per generation), and left and right corpora lutea $(.04 \pm .01$ and $.05 \pm .01$ per generation, respectively) over the 21 generations were all significant $(P<.05)$. The regression for total ova success was not significantly different from zero, but this was consistent with the goal of index selection in this study.

These results build on the findings reported after 13 generations of selection by Gion (1989). At Generation 13, the regression of response on generation number for index was significant $(.08 \pm .02$ index units, $P<.10$ ), but not for the component traits. There was more variability in left, right, and total corpora lutea across the three replicates at Generation 13 than at Generation 21. Regressions over 21 generations have a greater chance of exhibiting significance than do regressions over 13 generations. A special evaluation conducted at Generation 13 (Gion et al., 1990) indicated that increased ovulation rate was the primary factor responsible for the increase in number born. A second reason cited for the increase in number born was a slight decrease in ova loss, the difference between ovulation rate and total number born. At Generation 21, ovulation rate still seemed to be the primary factor responsible for the increase in number born. Ova loss, the difference between number of ova shed and the total number born, was not analyzed in this data set. However, ova success, the ratio of total number born to number of ova shed, was evaluated and it did not seem to have changed. Although ova success did not increase it also did not decrease, even with the increase in ovulation rate; thus, the ability of the dam to support more fetuses had been improved.

Female Mating Weight. The average female BW at mating increased in each criterion of selection and decreased slightly in the control. Regressions of selection criteria (deviated from LC) on generation number for IX, LS, and UT were $.11 \pm .00(P<.01)$, $.13 \pm .03(P<.05)$, and $.05 \pm .02(P<.10)$ grams per generation, respectively. The change in mating weight in LC was negative across all replicates, $-.06 \pm .02 \mathrm{~g}$ per generation $(P<.10)$. The resulting changes after 21 generations of selection were larger than those noted at Generation 13.

Eisen and Durrant (1980) found that for each additional gram of BW at mating, litter size increased by .42 pups. In the present study, total number born was regressed on female mating weight, and regression coefficients for IX, UT, LS, and LC, replicates pooled, were $.37 \pm .13(P<.11), .24 \pm .04(P<.05)$, $.44 \pm .07(P<.05)$, and $.26 \pm .07(P<.10)$ pups per gram, respectively. Thus, for every gram increase in 
female BW at mating, litter size was increased by .24 to .44 pups, depending on the selection criterion. Fertility. Although there was a significant $(P<$ $.001)$ quadratic change in pregnancy rate over generations of selection, the criteria did not differ $(P>.20)$ in their responses. In the analyses of the last seven generations (15 through 21) of selection and the generations (22 through 27) of relaxed selection, the criteria did not differ $(P>.50)$. The mean pregnancy rates were 93.6, 95.7, 93.9, and 95.0 in Generations 15 through 21 and 96.7, 96.8, 97.2, and 97.0 in Generations 22 through 27 for IX, LS, UT, and LC, respectively.

Inbreeding. Mean inbreeding coefficients after 21 generations of selection were fairly uniform across IX, $\mathrm{UT}$, LS, and LC $(.25, .24, .26$, and .22 , respectively, averaged for the three replicates). At Generation 27, due to the increase in population size, these respective levels of inbreeding were $.29, .30, .28$, and .27 . Falconer (1960) estimated the effect of inbreeding on reproductive performance in mice to be negative: for every $10 \%$ increase in inbreeding, litter size and offspring viability are expected to decrease by approximately .5 and .245 pups per litter, respectively. Accumulated inbreeding would help explain the negative change over time in LC. However, the rate of inbreeding was slow, there was some selection to offset any effect, and environmental changes may also have been positive. Thus, the decrease in litter size in the LC due to inbreeding was not as large as would be predicted using Falconer's data.

Discussion. Selection using an index made up of ovulation rate and ova success, selection for uterine capacity, and selection directly on litter size were all effective means of increasing the total number born in mice. Regressions of deviation from control on generation number over 21 generations were very similar for total number born (litter size) in the IX and LS selection criteria, .14 and .16 pups, respectively. The IX selection, as predicted, seemed to be better than LS through the early part of the selection. However, it was poorer during later generations, probably due to failure to change the index to an optimal one, given changing underlying parameters. Total response of approximately four pups in our experiment for LS selection compares favorably with the response of four pups after 15 generations (Joakimsen and Baker, 1977) and six pups after 23 generations (E. J. Eisen, personal communication) or 29 generations (Bakker et al., 1978) in other experiments with mice. Response in number born (uterine capacity) to the UT selection criterion also was positive, but smaller (.09 pups per generation), as might be expected when selecting for increased number of embryos in a more crowded uterine environment.

Although total uterine capacity in the pig seems to be simply twice that observed in number born in the unilaterally ovariectomized-hysterectomized sow
(Christenson et al., 1987), one cannot simply double number born in the unilaterally ovariectomized mouse to measure total uterine capacity. Thus, establishment of whether ovulation rate or uterine capacity is most lacking, hence discovering in which component improvement would yield the most response in litter size (Bennett and Leymaster, 1989, 1990), is not clear. Selection on UT resulted in response in our measurement of uterine capacity of 1.8 pups over the 21 generations and was at least as much as that observed in litter size ( 1.7 pups) during the relaxed selection phase. Combined emphasis on both ovulation rate and uterine capacity is needed in selection when both have similar means (Bennett and Leymaster, 1990). A study on uterine capacity, measured in both uterine horns and all criteria, has been conducted and will be reported in the future.

Realized cumulative selection differentials for IX, LS, and UT were 32.8 index units, 36.4 pups, and 28.5 pups, respectively. Unintended selection in LC yielded a cumulative selection differential of 3.3 pups. Even though LS had a higher selection differential than IX, response in number of pups born per unit selection was very comparable, .10 pups per unit of selection. If similar cumulative selection could have been achieved in IX and LS by increasing intensity in IX and(or) variability, then these two criteria would have been similar in response achieved. The response in UT, per unit of selection, was slightly less (.08 pups per unit of selection) than that in IX and LS.

For LS selection, all measures presented of response per selection applied (Tables 2 and 3 ) are realized heritabilities for litter size. Over the 21 generations, this heritability was .10 to .12 , which compares very closely to the .11 realized in 29 generations of selection for litter size in mice by Bakker et al. (1978) but is lower than the .18 to .22 reported in shorter experiments (11 to 15 generations) by Bradford (1968), Joakimsen and Baker (1977), and Eisen (1978). For UT selection, measures of response per selection applied through Generation 21, by not Generations 22 through 27, are estimates of realized heritability (.08) for uterine capacity, as defined in this paper.

\section{Implications}

Selection to increase litter size in mice is effective. Alternative selection criteria of an index of components and of uterine capacity have been effective in changing litter size. Optimally weighting components will produce more change than simply using number born as a criterion for selection. Improvement of number born per dam in livestock species through selection can be achieved and may be enhanced by methods incorporating components of litter size. 


\section{Literature Cited}

Bakker, H., J. H. Wallinga, and R. D. Politiek. 1978. Reproduction and body weight of mice after long-term selection for large litter size. J. Anim. Sci. 46:1572.

Bennett, G. L., and K. A. Leymaster. 1989. Integration of ovulation rate, potential embryonic viability and uterine capacity into a model of litter size in swine. J. Anim. Sci. 67:1230.

Bennett, G. L., and K. A. Leymaster. 1990. Genetic implications of a simulation model of litter size in swine based on ovulation rate, potential embryonic viability and uterine capacity: II. Simulated selection. J. Anim. Sci. 68:980.

Bradford, G. E. 1968. Selection for litter size in mice in the presence and absence of gonadotropin treatment. Genetics 58:283.

Christenson, R. K., K. A. Leymaster, and L. D. Young. 1987. Justification of unilateral hysterectomy-ovariectomy as a model to evaluate uterine capacity in swine. J. Anim. Sci. 65:738.

Clutter, A. C., M. K. Nielsen, and R. K. Johnson. 1990. Alternative methods of selection for litter size in mice: I. Characterization of base population and development of methods. J. Anim. Sci. 68:3536.
Eisen, E. J. 1978. Single-trait and antagonistic index selection for litter size and body weight in mice. Genetics 88:781.

Eisen, E. J., and B. S. Durrant. 1980. Genetic and maternal environmental factors influencing litter size and reproductive effi. ciency in mice. J. Anim. Sci. 50:428.

Falconer, D. S. 1960. The genetics of litter size in mice. J. Cell. Comp. Physiol. 56(Suppl. 1):153.

Falconer, D. S. 1971. Improvement of litter size in a strain of mice at a selection limit. Genet. Res. 17:215.

Gion, J. M. 1989. Alternative methods of selection for litter size in mice: Results from thirteen generations. M.S. Thesis. Univ. of Nebraska, Lincoln.

Gion, J. M., A. C. Clutter, and M. K. Nielsen. 1990. Alternative methods of selection for litter size in mice: II. Response to thirteen generations of selection. J. Anim. Sci. 68:3543.

Joakimsen, O., and R. L. Baker. 1977. Selection for litter size in mice. Acta Agric. Scand. 27:301.

Johnson, R. K., D. R. Zimmerman, and R. J. Kittok. 1984. Selection for components of reproduction in swine. Livest. Prod. Sci. 11: 541 . 